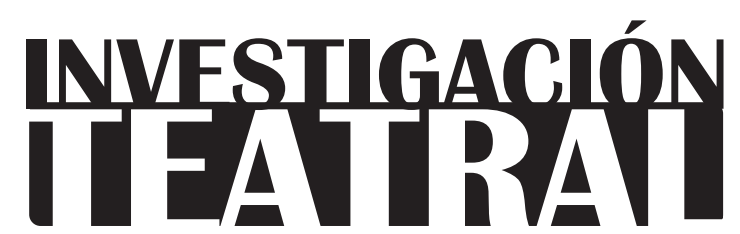

Revista de artes escénicas y performatividad

Vol. 10, Núm. 15

abril-septiembre 2019

Segunda época

ISSN impreso: 1665-8728

ISSN electrónico: 2594-0953

Universidad Veracruzana

In memoriam:

\title{
Arturo Meseguer Lima (1956-2019)
}

Francisco Beverido Duhalt*

\footnotetext{
"Centro de Documentación Teatral "Candileja", Xalapa, Veracruz, México.

e-mail: candilbever@yahoo.com.mx.
} 


\section{In memoriam:}

\section{Arturo Meseguer Lima (1956-2019)}

rturo Meseguer Lima era oriundo de la Ciudad México, pero vivió en Xalapa, Ve-
racruz, desde temprana edad, y descubrió el teatro cuando era adolescente. A prin-
cipios de los años 70, fue miembro fundador de la compañía Ateneum -el nombre con el que el director Raúl Zermeño, a su llegada de Polonia, re-bautizó la reestructuración de la Compañía de Teatro de la Universidad Veracruzana-, aunque no descarto alguna posible participación anterior, arrastrado por Enrique Pineda, en la efímera aventura de una carpa instalada en el Parque Juárez de la ciudad de Xalapa, donde se presentó por primera vez el monólogo La virgen loca, de Hosmé Israel.

Su primera participación como actor fue en Mazatecos (1975), una puesta en escena de Mario Alcántara, la cual se pretendía que fuera una reivindicación de ese grupo indígena. Desde ese momento, su dedicación, su interés y, sobre todo, su energía quedaron patentes, participando en todas las actividades que había en el programa de trabajo de la compañía: clases de teatro, de danza y de gimnasia. Desde ese momento, el teatro se convirtió en una de sus dos pasiones; la otra era el son jarocho, en el que se dedicó, con igual entusiasmo, a la jarana y al canto.

A pesar de ser parte del mismo grupo durante muchos años, tuvimos pocas participaciones conjuntas, aunque nos cabe el orgullo de haber sido parte del elenco de la primera obra de nuestra universidad en haber alcanzado - y develado una placa por- las cien representaciones: ¿Alguien dijo dragón?, de Carlos Lyra (1976), bajo la dirección de Jorge Castillo. Si bien mi personaje era el del galán joven -Juanito-, el verdadero protagonista era el personaje de Arturo -Tizón-, un niño mulato, a quien por esa razón todos discriminaban, incluso el Hada Madrina. 
INVESTIGACIÓNTEATRAL

Revista de artes escénicas y performatividad

Vol. 10, Núm. 15

abril-septiembre 2019
In memoriam:

Arturo Meseguer Lima (1956-2019)

Francisco Beverido Duhalt

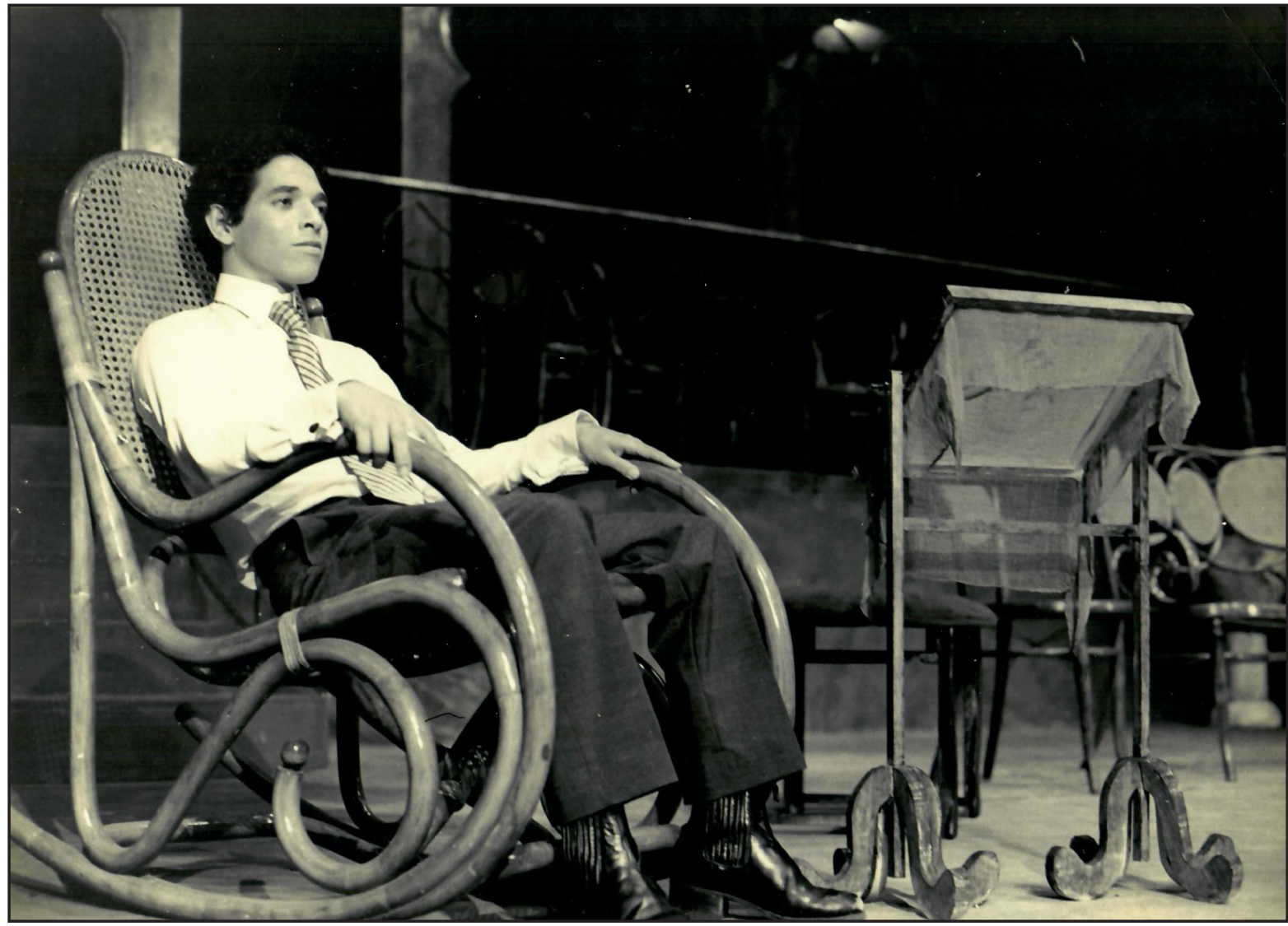

Arturo Meseguer en la obra El viaje superficial, de Jorge Ibargüengoitia, dirección de Raúl Zermeño. 1978. Foto cortesía de la familia Meseguer.

Volvimos a colaborar varias veces más: en La Atlántida, de Óscar Villegas (1976), y en Ivonne, Princesa de Borgoña, de Witold Gombrowicz (1978), ambas bajo la dirección de Marta Luna, así como en la memorable puesta en escena de Los signos del Zodíaco, de Sergio Magaña (1977). Pero sus papeles más importantes o más significativos fueron en otras obras: El viaje superficial, de Jorge Ibargüengoitia (1978), con dirección de Raúl Zermeño (donde su personaje hacía mancuerna con el de Enrique Pineda) y, sobre todo, en la inolvidable Los bajos fondos, de Gorki, dirigida por Julio Castillo (1979).

Más adelante, volvió a hacer mancuerna con Enrique Pineda en la efímera "Infantería Teatral”, desde su primera puesta en escena: Santa Catarina, de Óscar Villegas, en 1980. Si bien el grupo tuvo una duración muy breve, apenas cuatro años, logró algunas de los trabajos más importantes de aquella época para la universidad: Cúcara y Mácara (1980); 
La Ñonga, de Óscar Liera (1981); La última carcajada de Rosa Pérez, de Guillermo Garza (1982), y La pira, de Óscar Villegas (1983). Al regreso de Raúl Zermeño en 1984, quien reunió las tres compañías existentes, más los Talleres Libres de Actuación, en un solo grupo al que llamó Organización Teatral de la Universidad Veracruzana (Orteuv), se integró a ésta última y participó en muchas de sus puestas en escena importantes, entre ellas: ¿Cierren las puertas! (1988) y Veracruz, Veracruz, de Víctor Hugo Rascón Banda -estrenada en 1994, como parte de las actividades conmemorativas del Cincuentenario de la Universidad Veracruzana-.

No podemos olvidar su participación en Reflejos, un espectáculo de pantomima dirigido por Alejandro Morán en 1978, o en Los niños de otro planeta, una puesta en escena con títeres dirigida, ese mismo año, por Mercedes de la Cruz. Hay que mencionar, además, la experiencia de teatro experimental al aire libre de un taller impartido también en 1978 por Rense Royaards, del grupo Het Werkteatre de Ámsterdam, con la que Marco Antonio Montero buscaba ampliar los conocimientos y habilidades, así como diversificar las actividades de la compañía para no centrarlas en el teatro formal.

Si no me equivoco, su primer trabajo como director de escena fue en 1983 cuando, para celebrar un aniversario del espacio escénico "La Caja", se organizó una "Cruzada Teatral" por la ciudad, presentando varios espectáculos al aire libre. Uno de ellos fue El rey mono contra el demonio de hueso blanco (1983), un cuento tradicional chino adaptado y dirigido por Arturo con el Taller Coreográfico de la Universidad. A ella le siguieron, entre otras, $\mathrm{Ca}$ mino a Tokaido, de Dolly Velasco (1985); Cuento de navidad, de Emilio Carballido (1984); Octubre terminó hace mucho tiempo, de Pilar Campesino (1991), entre otras.

A principios de los 90, descubrió el Festival de Teatro Universitario e inició su actividad como funcionario: organizó de la edición XI (1986) a la XVI (1994). Fue por su iniciativa que, tras una interrupción de diez años y con el apoyo de los rectores Raúl Arias Lovillo, primero, y de Sara Ladrón de Guevara, después, la universidad retomó los Festivales Universitarios en 2012, de cuya organización se ocupó en los últimos años y que le incitó a organizar, con un esquema parecido, el Festival de Coros Universitarios, entre otras muchas cosas.

A pesar de ser abuelo -su hijo Camil, además de las satisfacciones de verlo como un músico profesional de alcances internacionales, le obsequió esa otra satisfacción-, Arturo nunca dejó de ser el eterno adolescente. Siempre fue "acelerado", "energético", vigoroso y vital; lo único que podía ponerle freno -a veces- era su disciplina y su rigor para todo lo que hacía, soñando y proyectando siempre nuevas cosas o cómo mejorar y superar las existentes. Aparentemente desperdigado, difuso, era capaz de concentrarse en varias cosas a la vez. Entregado no sólo a su trabajo, sino también a los que le rodeaban, participaba -en el mejor y más amplio sentido del término- con quienes compartían la escena con él. Muchos 
INVESTIGACIÓNTEATRAL

Revista de artes escénicas y performatividad

Vol. 10, Núm. 15

abril-septiembre 2019
In memoriam:

Arturo Meseguer Lima (1956-2019)

Francisco Beverido Duhalt

de los participantes en los casi diez festivales de los últimos años tienen presente su imagen cariñosa, entusiasta y su capacidad de liderazgo.

Arturo dejó inconcluso su proyecto de publicar una memoria por los 50 años del Festival de Teatro Universitario, al que adoptó con el mismo cariño con el que abrazaba todas sus empresas. No pudo completar su reto mayor -al que supongo que se le hizo difícil acostumbrarse-: la Dirección de Difusión Cultural de la Universidad Veracruzana, cargo que asumió en 2018. Su "acelere" le hizo adelantarse a muchos de nosotros y, por lo pronto, el Festival de Teatro Universitario ha quedado huérfano, mientras que la universidad ha perdido a uno de los personajes centrales de sus actividades culturales. 